San Jose State University

SJSU ScholarWorks

Master's Theses

Master's Theses and Graduate Research

1989

\title{
Student nurses' experiences \& perceptions of intuitive knowledge in nursing practice
}

Heather A. M Collie

San Jose State University

Follow this and additional works at: https://scholarworks.sjsu.edu/etd_theses

\section{Recommended Citation}

Collie, Heather A. M, "Student nurses' experiences \& perceptions of intuitive knowledge in nursing practice" (1989). Master's Theses. 3181.

DOI: https://doi.org/10.31979/etd.h6p3-mkbu

https://scholarworks.sjsu.edu/etd_theses/3181

This Thesis is brought to you for free and open access by the Master's Theses and Graduate Research at SJSU ScholarWorks. It has been accepted for inclusion in Master's Theses by an authorized administrator of SJSU ScholarWorks. For more information, please contact scholarworks@sjsu.edu. 


\section{INFORMATION TO USERS}

The most advanced technology has been used to photograph and reproduce this manuscript from the microfilm master. UMI films the text directiy from the original or copy submitted. Thus, some thesis and dissertation copies are in typewriter face, while others may be from any type of computer printer.

The quality of this reproduction is dependent upon the quality of the copy submitted. Broken or indistinct print, colored or poor quality illustrations and photographs, print bleedthrough, substandard margins, and improper alignment can adversely affect reproduction.

In the unlikely event that the author did not send UMI a complete manuscript and there are missing pages, these will be noted. Also, if unauthorized copyright material had to be removed, a note will indicate the deletion.

Oversize materials (e.g., maps, drawings, charts) are reproduced by sectioning the original, beginning at the upper left-hand corner and continuing from left to right in equal sections with small overlaps. Each original is also photographed in one exposure and is included in reduced form at the back of the book.

Photographs included in the original manuscript kave been reproduced xerographically in this copy. Higher quality $6 "$ " 9 " black and white photographic prints are available for any photographs or illustrations appearing in this copy for an additional charge. Contact UMI directly to order.

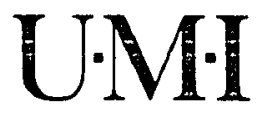

University Microfilms International

A Bell \& Howell Information Company

300 North Zeeb Road. Ann Arbor, MI 48106-1346 USA

$313 / 761-4700 \quad 800 / 521-0600$ 

Order Number 1339607

Student nurses' experiences \& perceptions of intuitive knowledge in nursing practice

Collie, Heather Ann Margaret, M.S.

San Jose State University, 1989

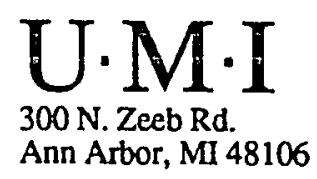





\title{
STUDENT NURSES' EXPERIENCES \& PERCEPTIONS OF INTUITIVE KNOWLEDGE IN NURSING PRACTICE
}

\author{
A Thesis \\ Presented to \\ The Faculty of the Department of Nursing \\ San Jose State University \\ In Partial Fulfillment \\ of the Requirements for the Degree \\ Master of Science
}

By

Heather A.M. Collie

December, 1989 
APPROVED FOR THE DEPARTMENT OF NURSING

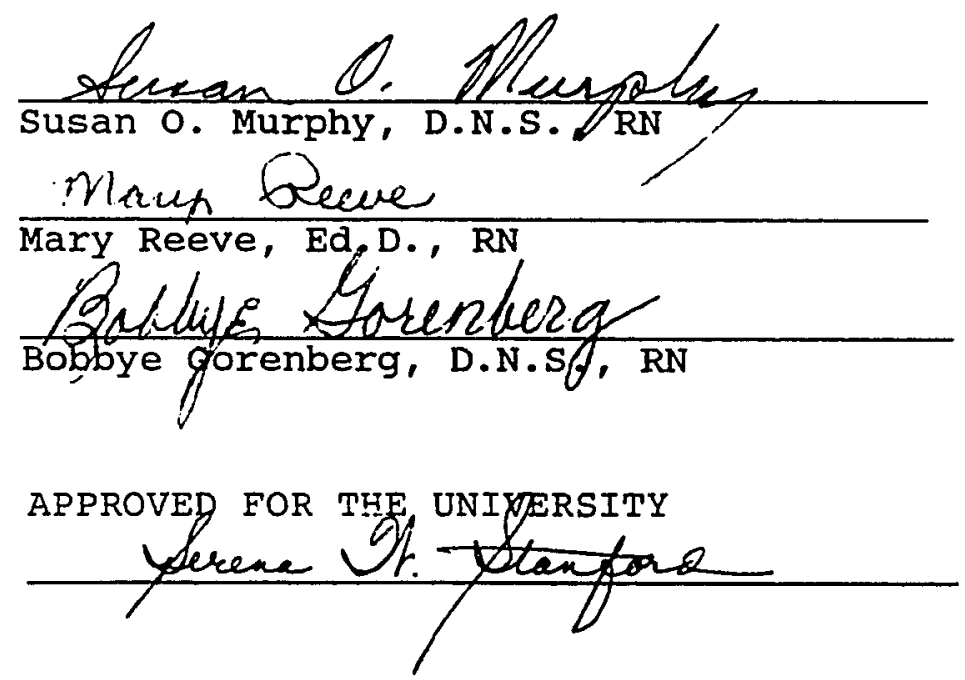


Warm and sincere thanks to susan Murphy for her devotion to higher education and her belief in excellence. I wish to thank Mary Reeve and Bobbye Gorenberg for their time and energy in preparing the manuscript. Special thanks to my parents for their years of support, encouragement, and guidance. A special note of thanks and appreciation to my grandmother, Ann Diplock, for her unconditional love. Many thanks to my fiancee, Bruce Chase, for his patience, love, and understanding. 


\author{
ABSTRACT \\ Student Nurses' Experiences \& Perceptions of Intuitive \\ Knowledge in Nursing Practice \\ by Heather A.M. Collie
}

This study addressed student nurses' experiences and perceptions of intuition in nursing and nursing education. The researcher used a multiple method approach, which provided both a general view and in-depth view of the students' opinions. In the initial phase, the researcher administered a demographic sheet and a questionnaire to 67 junior nursing students at a university in northern California. The second phase consisted of in-depth interviews with 10 of these students. The data collected from the initial phase was analyzed by computing an "intuition score" and comparing these values with the demographic information. The interviews were transcribed and content analysis was used to reduce the qualitative data. The findings suggested that student nurses did experience intuition in their nursing practice and placed value on this ability. Categories of how they perceived and experienced intuition were identified. Implications of this study involve both nursing practice and nursing education. 
TABLE OF CONTENTS

Page

IIST OF TABLES...................... vi

IIST OF FIGURES...................... vii

Chapter

1. INTRODUCTION.................... 1

2. THEORETICAL FRAMEWORK AND LITERATURE REVIEW. 2

3. METHODOLOGY...................... 19

4. ANALYSIS AND INTERPRETATION OF THE DATA.... 27

5. CONCLUSIONS AND RECOMMENDATIONS.........44 44

REFERENCES.......................... 48

BIBLIOGRAPHY ....................... 51

APPENDIXES........................... 53

A. Cover sheet.................... 54

B. Demographic sheet.............. 55

C. Questionnaire................. 58

D. Contact sheet.................6 60

E. Written Consent Form............. 62

F. Interview Guide............... 64

G. IBR Approval Letter.............666 


\section{LIST OF TABLES}

Table Page

1. Total Number of Years Employed in

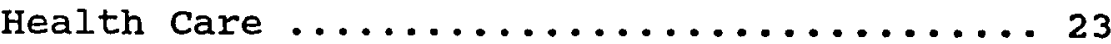

2. Intuition Scores for 65 subjects one Bin for each Response....................28

3. Responses to Question 4 for 65 subjects...... 30 


\section{LISTS OF FIGURES}

Figure

Page

1. Agreement with Question 4 as a function of Intuition score......................... 31 
Chapter 1

INTRODUCTION

Historically, the profession of nursing has wrestled with a number of challenging issues which supported conducting this research. One of these historical issues is the need to define and clarify the nature of nursing practice. Defining our practice is important for the purpose of expressing nursing's unique way of viewing interacting with and responding to clients. clear articulation of this unique view directly influences every nurse in her or his nursing practice.

Carper (1978) eloquently writes of this unique perspective and the importance of defining it:

Nursing practice has patterns, forms and structure that serve as horizons of expectations and exemplify characteristic ways of thinking about phenomena. Understanding of these patterns is essential for the teaching and learning of nursing. (p. 13)

Benner (1984) has contributed to this endeavor by clarifying the different characteristics of novice and expert nurses. Specifically, she describes the use of intuitive knowledge, in conjunction with clinical decision making, as a characteristic of the expert nurse. Discussion 
of how nurses specifically use and develop this intuitive knowledge is an essential part of understanding this unique view.

Other nursing researchers strongly suggest that intuition has a role in clinical decision making (Rew, 1987; Schraeder \& Fischer, 1986). Although intuition alone may not be adequate in shaping decisions, these scholars agree that intuitive clues do guide expert nurses when making clinical decisions.

Nursing education has a responsibility to teach nursing students both physical and mental skills which facilitate the practice of quality nursing. Since it is apparent that expert practice involves use of intuitive knowledge, it follows that nursing education should teach students both intuitive and scientific ways of thinking.

Rew (1987) suggests that the emphasis on scientific reasoning in nursing education may not provide the novice with the opportunity to develop intuitive thinking skills. She suggests that nursing research and education find ways of cultivating this innate ability.

Bastick (1982) proposes that intuition is basic to the educational process. He recommends that students be encouraged to use and develop a sense of intuitive ability. He suggests that a general intuitive feel is needed so the 
student may piece together a coherent picture.

It is evident that nursing education has a need to address the role of intuition in nursing education and practice. Prior to making curriculum changes there is a need to understand how nursing students experience intuition in their nursing practice and how they view the use of intuitive knowledge in general.

Purpose and Research Questions

The specific aim of this study was to examine how nursing students perceive and experience intuition in their nursing practice.

This research investigated the following questions:

1. How do junior level nursing students view intuition as it relates to nursing?

2. How have nursing students experienced intuition in their own nursing education and practice?

These questions were addressed by the researcher using both a qualitative and quantitative approach. The initial phase of the research (Phase one), consisted of administering a questionnaire, developed by the author, to 67 junior nursing students (see Appendix c). The second phase (Phase Two), involved in-depth taped interviews, following an interview guide with 10 nursing students (see Appendix F). Prior to conducting this research permission 
was obtained from the IRB at the northern California university (see Appendix G).

The scope of this research was limited to one nursing school in northern California and involved one class level of nursing student. Limitations of this study include a relatively small sample size and unknown reliability and validity of the questionnaire.

This chapter has provided the reader with a brief introduction to the background of this issue and the research questions. The following chapter will provide the reader with an in-depth review of the related literature. 


\section{Chapter 2}

THEORETICAL FRAMEWORK AND LITERATURE REVIEW

The following discussion will explain the broader theoretical roots regarding intuition from education and philosophy and will discuss Benner's work which is relevant to this study. However, the reader needs to understand that this study is not designed to apply or test a specific framework; rather, the concepts, hypotheses, and constructs come from the data.

A variety of disciplines have been concerned with the phenomenon of intuition. Raucators have been concerned with intuition in learning, philosophers with intuitive knowledge, and psychologists as intuition relates to personality. Regardless of the specific discipline's focus, the literature reflects the history of human excitement and marvel with the experience of intuition. This multidisciplinary interest in intuition reflects the universality of this phenomena. Intuition is an exciting experience that is shared by all of humanity.

According to Wescott (1968) there are three general categories which reflect philosopher's view of intuition. They are classical intuitionism, contemporary intuitionism, and inferential intuitionism. 
Wescott's overview of the major schools of thought of philosophers, illustrates the differences within this discipline regarding the definition and significance of intuition. Classical intuitionism, views intuition as a special way of obtaining special knowledge. It is a unique experience that can not be shared with others. Intuition can be encouraged, however typically it is seldom utilized by individuals. Bergson believed intuition is direct contact with prime reality. Spinoza felt intuition provided a superior way of knowing, that it is mystical, supernatural knowledge that is god sent. Croce viewed intuition as ultimate beauty (Wescott, 1968).

Contemporary intuitionism views intuition in a more calculated manner. This group believes intuition is elementary and a basic truth of deductive logic, or causality, this is a part of the external reality which supports the notion of intuition (Wescott, 1968).

The school of thought called Inferential Intuitionism, views intuition as a mental exercise which by-passes the analysis of the information available. Intuits are merely hypotheses which are arrived at by individuals who lack empirical testing of the hypotheses (Wescott, 1968).

Wescott's review of psychology also reveals a long standing debate regarding intuition. Carl Jung, the first 
modern psychologist to directly address intuition, viewed intuition as a part of personality rather than knowledge. He viewed it as one of four mental functions. Jungian Typology is based upon thinking, feeling, sensation and intuition. Intuition is irrational, non-judgmental, and its function is to perceive all possibilities at the expense of details. All four mental functions are present in all individuals; however, each person has the propensity towards the use of one in particular. Jung believed that two of the mental functions were mildly developed and one was primarily unconscious, undeveloped. An intuitive individual "knows" without knowing why or how he knows (Wescott, 1968). Wescott (1968) suggests that intuition occurs when an individual reaches a conclusion on the basis of less explicit information than is ordinarily required to reach that conclusion. This definition focuses on the behavioral aspect of intuition.

Fallik and Eliot (1985) investigated intuition, cognitive style, and hemispheric processing by administering the following tools to 200 undergraduate students: Wescott's test of intuitive ability, Witkin's group embedded figures test, Paivio's revised individual differences questionnaire and visual and aural dominance measurements. Their results suggested that there is no sex-related linkage to intuition. 
The research did not support a connection between hemispheric basis with intuitive performance.

Fallik and Eliot (1986) investigated correlations between intuition and college majors. Their results indicated that older subjects were less intuitive than younger subjects, and physical science majors were more intuitive than education majors.

Intuition is used by many as a method of problem solving. Bruner (1973) discusses the use of intuitive knowledge with mathematics. He suggests that the use of physical intuition is often what separates good physicists from the average. He speaks of the phenomenon as "intuitive familiarity" which is what gives an individual a serse of what combinations will be effective and which will not. Hubert Dreyfus (1979), in his book what Computers Can't Do, discusses the use of insight as an essential component when solving difficult problems. He suggests that when solving complex problems an individual must be able to view the problem as a composite of several smaller problems. Then the individual requires a depth of understanding of the situation in order to deduce or guess possible consequences. Dreyfus (1979) suggests that correct problem solving of complex problems requires not only the above mentioned prerequisite but also insight. 
Dreyfus and Dreyfus (1985) studied characteristics of fighter pilots. They were interested in what specific characteristics separated the novice pilot from the expert. They found that the experts had an "intuitive" grasp of their own ability along with the plane's and their wingman's ability. They stated that this intuitive method of problem solving had six aspects. First, there is pattern recognition which is the ability to recognize relationships without analysis of the separate factors. Similarity recognition occurs when an individual recognizes a situation, as either similar or dissimilar to prior experiences. The expert problem solvers also had a deep grasp of their environment. Dreyfus and Dreyfus refer to this as common sense understanding. The characteristic of skilled knowledge was described as the ability to perform a task quickly and accurately without detailed cognitive analysis. The skill of an expert seems to be instinctual. The pilots also had what is referred to as a sense of salience. This is the ability to prioritize events and situations in an order of importance. The sixth aspect is deliberative rationality; the expert knows what to expect in different situations.

Benner (1984) developed a model which explained the development of a nurse. She discussed this development by 
presenting specific characteristics that separate the novice from the expert. She adapted these levels from Dreyfus and Dreyfus (1985).

Level I is the novice, a beginner who has little, if any, experience and who needs a set of clear, concise rules to guide her practice. Level II is the advanced beqinner. This nurse has had some experience. However, she needs some assistance in prioritizing her actions. The third level is what Benner refers to as the competent stage. The competent nurse typically has practiced nursing 2 to 3 years.

She can incorporate long and short term goals and decide what aspects of a situation are important and which are not. Level IV is the proficient level. This nurse sees the situation as a whole, rather than in separate, compartmentalized components. Level $\mathrm{V}$, the final level, is the expert nurse. She does not rely on analytical principles to understand a clinical situation, rather she has a reservoir of experience to draw upon. She has an intuitive grasp of the situation and does not need to filter through extraneous elements in the situation. She has the ability to see patterns and identifies important elements immediately (Benner, 1984). Hammond, Kelly, Schneider, and Vancini (1966) studied the cognitive tasks involved in nursing assessment and 
actions with 212 patients experiencing post-surgical pain. They found that 17 different nursing actions were taken in the 212 cases studied. Each individual decision was influenced by cue characteristics; these numbered 165. This study strongly suggests that the cognitive aspects of these nursing actions are complex. The multitude of information a nurse must analyze in the decision making process is cumbersome. How a nurse makes these decisions accurately, and often immediately, is an important area of focus. Kelly (1966) further discusses the decision making process by describing features of clinical inferences used by nurses. She suggests that the following are characteristics of clinical inferences:

1. The inferences nurses make have high social significance.

2. The inferences nurses make are based on probabilistic and incomplete data.

3. The inferences nurses make are followed by immediate action.

4. The inferential tasks are complex.

Hammond (1966) discusses inductive inferences as an important form of knowing which is utilized by nurses when caring for patients. His particular area of interest lies with imperfect induction which occurs when an individual 
uses results of past experiences to predict future occurrences.

Hammond (1966) suggests that individual nurses must use their own intuitive inductive powers, termed clinical inference, when functioning in the clinical environment. He makes a strong case regarding the need for nurses and nurse educators to understand the dynamics of how a nurse assesses the state of patients and the decision making skills involved with the interventions that follow those assessments.

Rew and Barrow (1987) were interested in the prevalence of the topic of intuition in nursing literature. They traced and analyzed nursing literature published in the American Journal of Nursing between 1900 and 1985. Their conclusions were that intuition is a neglected area of nursing knowledge. They suggest that intuition in nursing needs to be explicitly acknowledged and discussed.

Intuition and the nursing practice was first addressed in 1965 by Mccain. She spoke of the need for nurses to focus on scientific methods of assessment rather than mere intuition. Since the 1960's emphasis on the "scientific mode" of reasoning has dominated the nursing literature. However, recent Iiterature suggests that nurses need not neglect this useful tool of intuitive knowledge. On the 
contrary, they should nurture it.

A qualitative study was conducted by Agan (1987) which investigated seven nurses' perceptions of holistic nursing. His findings suggested that nurses' perception of holistic nursing involves a nonrational, intuitive knowing as a dimension in their nursing practice. This study further discussed the credibility of intuitive knowing. It indicated that intuition is based upon individual, personal knowledge.

A theory of nursing gestalt was developed by Pyles and Stern (1983) to explain the cognitive processes used by experienced critical care nurses. They conducted in-depth interviews with 28 critical care nurses. They considered the decision-making processes used to determine if patients were going into cardiogenic shock. They discovered that the decision making was done by an operation in which the nurses link together basic knowledge, past experiences, sensory clues (which nurses referred to as "gut feelings"), and clues that were presented by the patients.

Schraeder and Fischer (1987) studied the use of intuitive knowledge by nurses in the neonatal intensive care nursery. They investigated factors that encouraged nurses to use intuitive knowledge. Methods used included interviews, direct observations, and examination of documents. Their 
research indicated that the factors which influence the use of intuitive knowledge were the amount of experience the nurse had, how well the nurse knew the infant, how she felt about the infant, what cues the infant gave the nurse, and the nurse's ability to connect the particular experience with past experience. Earlier research conducted by these researchers suggested that the ability of a nurse to act on intuitive knowledge included the nurse's strength of conviction and openness to information that is different from the available empirical data (Schraeder \& Fisher, 1986).

Young (1987) conducted a descriptive study by interviewing and observing 41 female subjects, 39 of whom were registered nurses. She used the information gathered to describe the phenomenon of clinical intuition. She proposed that clinical intuition has a functional dimension that consists of a process and product. The process is the interaction that the nurse has with the patient. The product is the knowledge received from this interaction. She labeled the expression of intuition, the judgement phase in which the nurse determines what actions will occur due to this new knowledge. Young's research indicated there is a validity phase in which the nurse evaluates the usefulness 
of the action taken in response to the clues. She estimated that $92 \%$ of the actions are correct responses.

Benner and Wrubel (1982) revealed that quality nursing care often involves the use of intuitive knowledge, which is developed over time. They voiced concern about the nursing shortage because inexperienced nurses lack the intuitive skills that expert nurses often possess. They explained that this experience-based intuition allows the expert the ability to have a grasp of the clinical situation, which can direct life-saving interventions.

Benner and Tanner (1987) conducted extensive research by interviewing expert nurses. They asked them to describe situations in which they used intuition. Many of the nurses responded with anecdotal descriptions of situations in which there was no evidence that their patients were in trouble or entering a crisis and yet the nurses responded as if a crisis was imminent. Often, the results were positive. Benner suggests that more research needs to be conducted regarding the validity of intuitive thinking, since nurses may selectively recall when their intuition proved them right.

Rew (1988) conducted detailed descriptive research involving intuition. She interviewed nurses and asked them how they experienced intuition in their nursing practice. 
She then transcribed the interviews and coded the responses of the subjects. She analyzed the nurses' definitions and found that the responses developed recognizable patterns. Nurses experienced intuition in either an affective, cognitive, or behavioral mode. The nurses' reaction to this intuitive experience precipitated various types of actions. The nurses were motivated to gather more information, validate the information received with objective information, corroborate with peers, report the findings, and, finally, initiate specific nursing interventions. Rew's research indicates that nurses arrive at decisions by evaluating more than just the apparent data. The research concludes clinical decision making involves the use of intuitive knowledge. Rew (1986) recommended additional research which focuses on how this phenomenon influences nursing practice. She states that it is imperative that the nursing profession recognize this concept and examine how nurses can develop this skill.

Gerrity (1987) states that while the nursing profession is attempting to define itself, its major area of concern has been science. She believes that the value of intuition may broaden the scope of nursing practice, and encourages nursing educators to incorporate this aspect of nursing into the curriculum. 
Bloomquist (1985) recommended that evaluation of students should involve both systematic check lists and the use of intuition. It is her belief that intuitive thinking may enable an individual to arrive at creative solutions. Rew (1987) believes that although nursing educators can not make intuitive experiences occur, they can encourage nurses to acknowledge these experiences. She suggests that the emphasis on scientific reasoning in nursing education may not provide the novice with the opportunity to develop intuitive thinking skills.

Miller and Rew (1989) discuss the importance of integrating both analytical reasoning and intuition in nursing education. They describe the problematic historical perspective of intuition in formal education. They believe intuitive knowledge can be fostered by teaching strategies which include mental imagery, focusing on the questions instead of the right answers, and lastly, teaching and encouraging nursing students to experience creative risk taking.

While reviewing the literature it becomes apparent that many nursing theorists, researchers, and educators, strongly support the idea that nurses use intuitive knowledge when caring for clients. Intuition becomes imperative to the nurses who make hundreds of significant clinical decisions 
each working day; often these decisions have life saving consequences.

since excellence in nursing practice begins with nursing education, nursing educators have an interest in the development of the intuitive potential. Nursing education's responsibility is to equip students with both physical and cognitive skills which will provide them with the ability to develop into expert practitioners. Therefore, this study investigated how one group of nursing students presently experience and perceive the role of intuitive knowledge in nursing. This study also provides educators with a better understanding of the junior level nursing students' view of the role education plays in the development of their intuition. 


\section{Chapter 3}

\section{METHODOLOGY}

This chapter will provide the reader with a description of the methods used in this research. The researcher used both quantitative and qualitative research methods to explore nursing students' perceptions and experiences of intuition. A demographic sheet, and a short questionnaire were administered to a large sample of junior nursing students at San Jose State University. Following this, the researcher conducted in-depth, open ended interviews with a smaller sample of these nursing students. This multiple method approach was selected because it provided the opportunity to explore both a general view as well as an indepth analysis of the subjects' perceptions and beliefs concerning intuition.

The sensitizing questions guiding this study included:

1. How do junior level nursing students view intuition as it relates to nursing?

2. How have nursing students experienced intuition in their own nursing education and practice? This chapter begins with a discussion of the questionnaire (Phase one) and follows that with a description of the individual interviews (Phase Two). 


\section{Data Collection: Phase one}

The initial phase of the study involved the administration of a demographic sheet and brief questionnaire on intuition. The questionnaire was designed by the researcher after a thorough review of the literature revealed the absence of appropriate research tools relating to intuition. The questionnaire consisted of seven questions. Five questions $(\# 1,2,3,5,6$,$) asked the student$ specifically how they felt intuition was used in nursing practice. Question 4 asked the student whether or not their nursing education supported their use of intuition. The students gave their responses on a 5 point likert scale, from "strongly agree" to "strongly disagree," with "indifference" being the mid-point, neutral value. The last question (\#7) was open ended, and asked the student to give a written example of when they had experienced intuition in their nursing practice.

Recruitment of the participants occurred on three separate occasions during scheduled nursing skills labs. The subjects were junior nursing students who were all enrolled in the same skills course, in three separate lab sections. There were 73 students enrolled in the course; 67 students were present in class and all received a questionnaire; 65 students completed the questionnaire. Two 
questionnaires were unusable since one was returned blank and another was only partially completed.

All the students were given a brief explanation of the study and were invited to participate in one or both phases of the study. The students were given the option not to participate. The students were told that completion of the demographic sheet and questionnaire implied consent to participate in the first part of the research; however, doing so did not obligate them to participate in an interview (see Appendix A). The students were then given the demographic sheet and questionnaire to fill out (see Appendix $B$ and $C$ ). The students completed this process in 15 minutes.

Data Collection: Phase Two

At the same time that students were recruited for the first phase, students were invited to participate in the interview. Those who were interested were asked to provide their name and phone number on a separate form (see Appendix D). Ten students expressed interest in the interview. The researcher contacted those students and scheduled individual appointments. At the time of the interview the participants were given the opportunity to review the research protocol and to give their written consent (see Appendix E). Prior to signing the consent, time was provided for the 
participants to ask questions regarding the research.

The interviews were conducted in a private room at a university in northern California. The researcher followed the interview guide (see Appendix F). The interview guide was developed for the purpose of exploring the subject's understanding of, and their meaning of intuition. Each interview was taped and lasted between 30 minutes to 1 hour. Sample

The subjects' ages ranged from 20 to 41 , with a mean age of 26.2 years, and a median of 23 years. Ninety-two percent of the subjects were female and $7.7 \%$ were male. The subjects' ethnicity was as follows: Asian, 18 (28\%); Caucasian, 37 (57\%); Hispanic, 4 (6.2\%); Black, O (0\%); other, 6 (9.2\%). Primary languages of the subjects included English 52, (80\%); Tagalog, 4 (6.2\%); Korean, I (1.5\%); Vietnamese, 1 (1.5\%); Chinese, 3 (4.6\%); no response, 4 $(6.2 \%)$. Thirty-one students $(48 \%)$ had an associate degree already and $4(6.2 \%)$ had a bachelor's degrees. The subjects' total number of years employed in health care ranged from none to more than 4. Thirty-five percent of the subjects had no work experience in health care; $22 \%$ of the subjects had less than 1 year; $12 \%$ had 2 to 3 years experience; $3 \%$ had 3 to 4 years experience; and $20 \%$ had over 4 years of experience (see Table 1 ). 
Total Number of Years Employed in Health Care

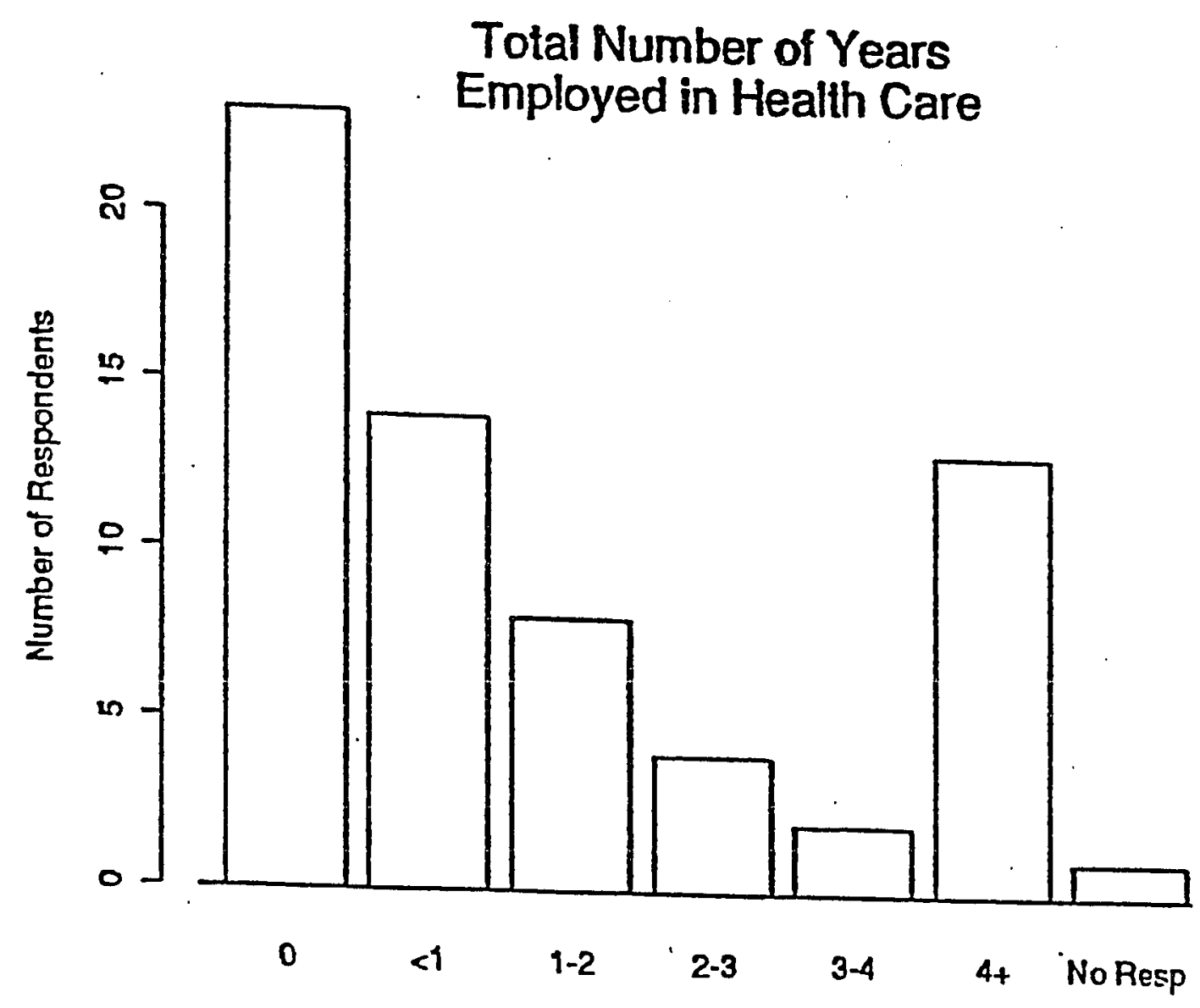


The interview subset of the original sample had the following demographic profile. The mean age was 31 years, with a range of 21 to 41 years. Of the 10 students, 5 already had an associate degree, one had a bachelors degree. Two students had less than a year of experience working in health care; 3 had 1 to 2 years of experience; and 6 had more than 4 years of work experience in the health care system. All of the students who volunteered for the interview listed English as their primary language. Data Analysis: Phase One

The questionnaire consisted of seven questions; analysis of these occurred in three segments. Answers to Number 7 were analyzed qualitatively, looking for themes or trends. Question 4 which related to the students' view of intuition and nursing education was analyzed separately because it was the only item relating to education. The 5 questions which related specifically to the students' view of intuition in nursing practice were analyzed together. This was done primary because of the author's interest in the degree to which the subjects believe that intuition is important in nursing practice. 
Thus, an "intuition score" was constructed. This was done by assigning the following values to each possible answer for questions $1,2,5$, and 6 .

$\begin{array}{lr}\text { Strongly agree } & 2 \\ \text { Agree } & 1 \\ \text { Indifferent } & 0 \\ \text { Disagree } & -1 \\ \text { Strongly disagree } & -2\end{array}$

For question 3 the values were reversed, yielding the following corresponding values:

Strongly agree -2

Agree $\quad-1$

Indifferent $\quad 0$

Disagree 1

strongly disagree 2

The values were opposite to that for questions, $1,2,5$, and 6 because this item was phrased in the opposite direction from the other 4 items.

The scores for each of these five questions were added together, yielding an "intuition score" for each student. The possible scores ranged from -10 to +10 . A score of +10 suggested that the student saw intuition as important; -10 suggested that they gave it little value. The resulting "intuition score" would be zero if the student gave an 
indifferent response to all five questions.

The creation of this "intuition score" does not imply that the score truly measures the attitudes or values of the participants. It merely provides a efficient method of summarizing the results. The researcher compared the intuition score to the demographic data to identify any associations between this information. Data Analysis: Phase Two

The interview data obtained on the second phase were transcribed and the lines were numbered. Qualitative analysis was directed toward identifying similarities and differences, major themes, and patterns.

This chapter has discussed the research design and methods used by the researcher to investigate how student nurses perceive and experience intuition. The following chapter will discuss the findings of both the questionnaire and the in-depth interviews. 
Chapter 4

ANALYSIS AND INTERPRETATION OF THE DATA

This chapter will discuss the findings from phase one (the questionnaire), followed by a discussion of the second phase (the interviews).

Findings: Phase one

As discussed in chapter 3, the five questions that related specifically to the students' view of intuition in nursing practice were analyzed together by constructing an intuition scale. The possible scores ranged from -10 to +10. The actual intuition scores of these subjects ranged from -3 to +10 . The mean score was 5.17 ; the median was 5 ; and the standard deviation was 2.63 (see Table 2). The researcher examined the data for associations or relationships between the intuition score and various demographic characteristics. There was no association between the subjects' age and their intuition scores. The intuition scores were compared with the subjects' reported race, primary language, years of experience in nursing, and education level. The researcher found no apparent associations between any of these variables and the intuition score. Intuition scores and respondents and nonrespondents to Question 7 were compared. No association existed between these factors. 
Table 2

\section{Intuition Scores for 65 Subjects One Bin for Each Possible Score}

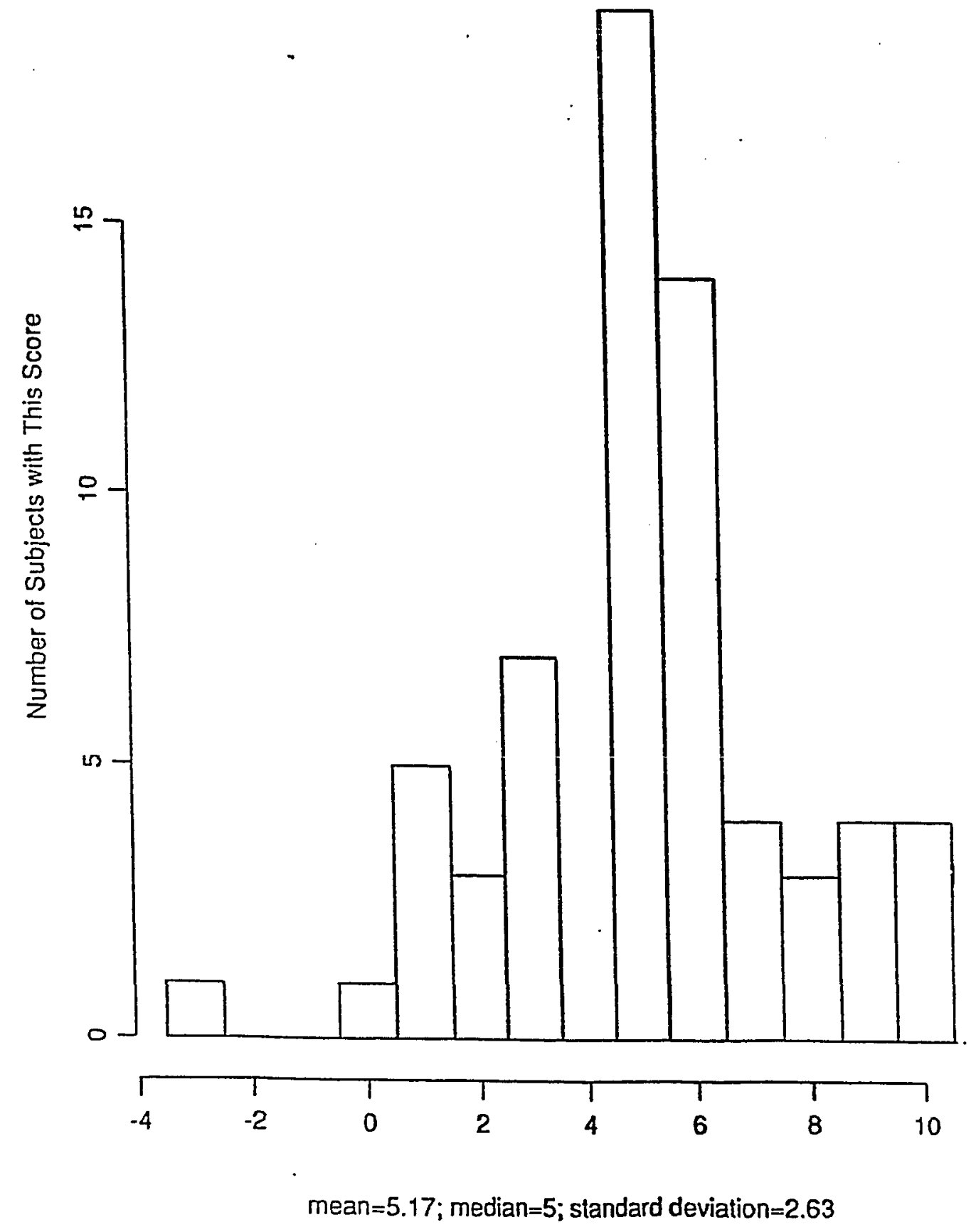


Question 4 was then analyzed. This question specifically addressed the students' view as to whether their nursing education supported their use of intuition. The question was stated, "My nursing program supports my use of intuition." The researcher gave the following values to the possible answers.

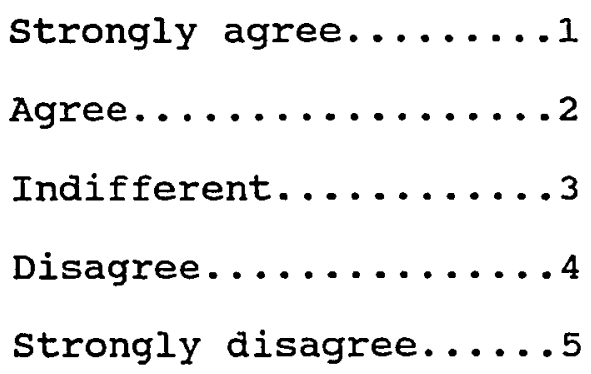

The mean response was 2.77 , the median 3 , and the standard deviation .97 . A weak trend existed that indicated the students believed that their educational program supported their use of intuition (see Table 3).

The researcher examined the relationship between agreement on Question 4 as a function of intuition score. There was a weak association between intuition scores and agreement on Question 4: The higher the intuition score, the more strongly they agreed with question number 4 (see Figure 1).

The short answer question (\#7) read, "Describe a clinical situation when you used or observed intuition being used." Forty-six percent of the subjects responded to this 
Table 3

Responses to Question 4 for 65 Subjects

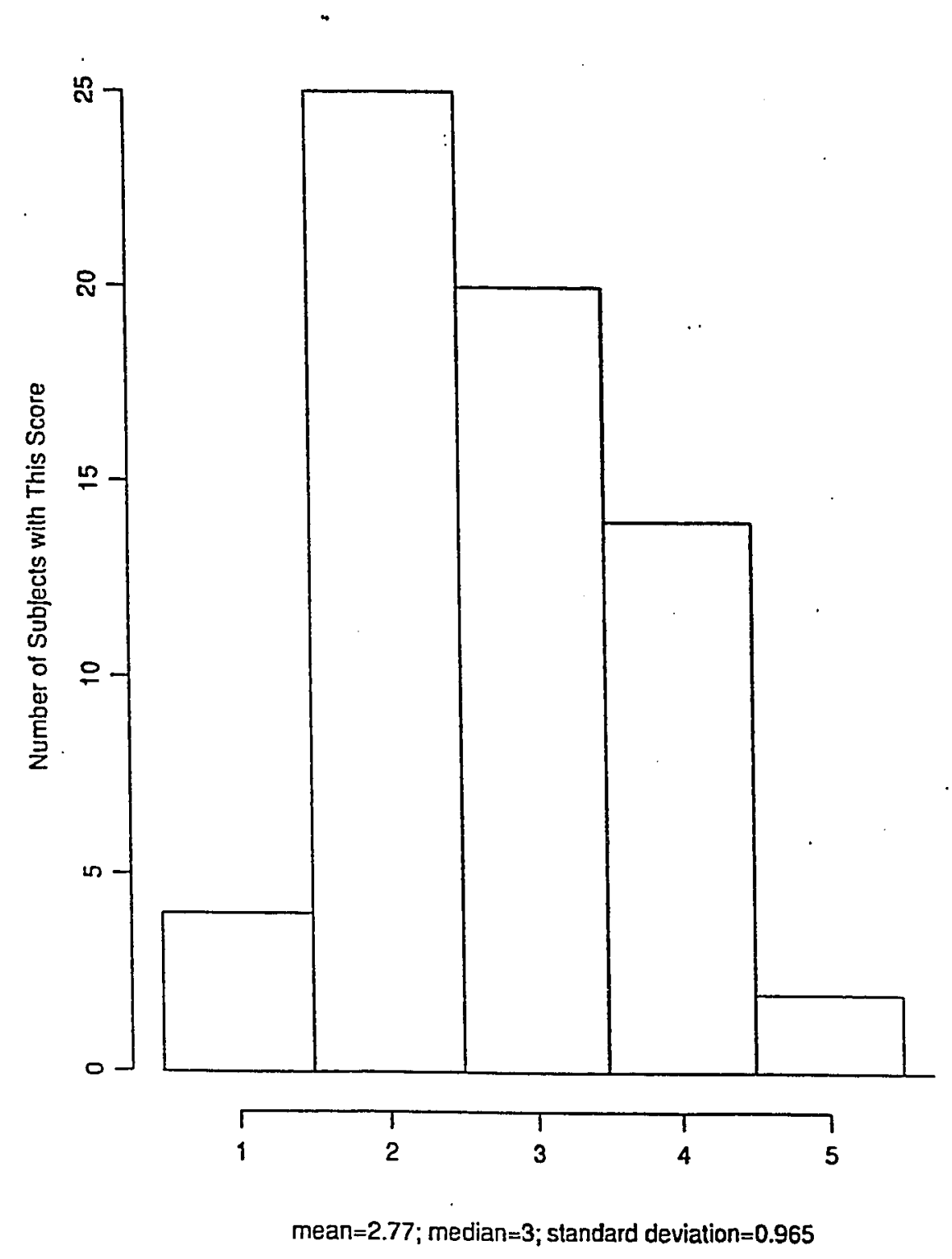


Agreement on Question 4 as a function of Intuition Score

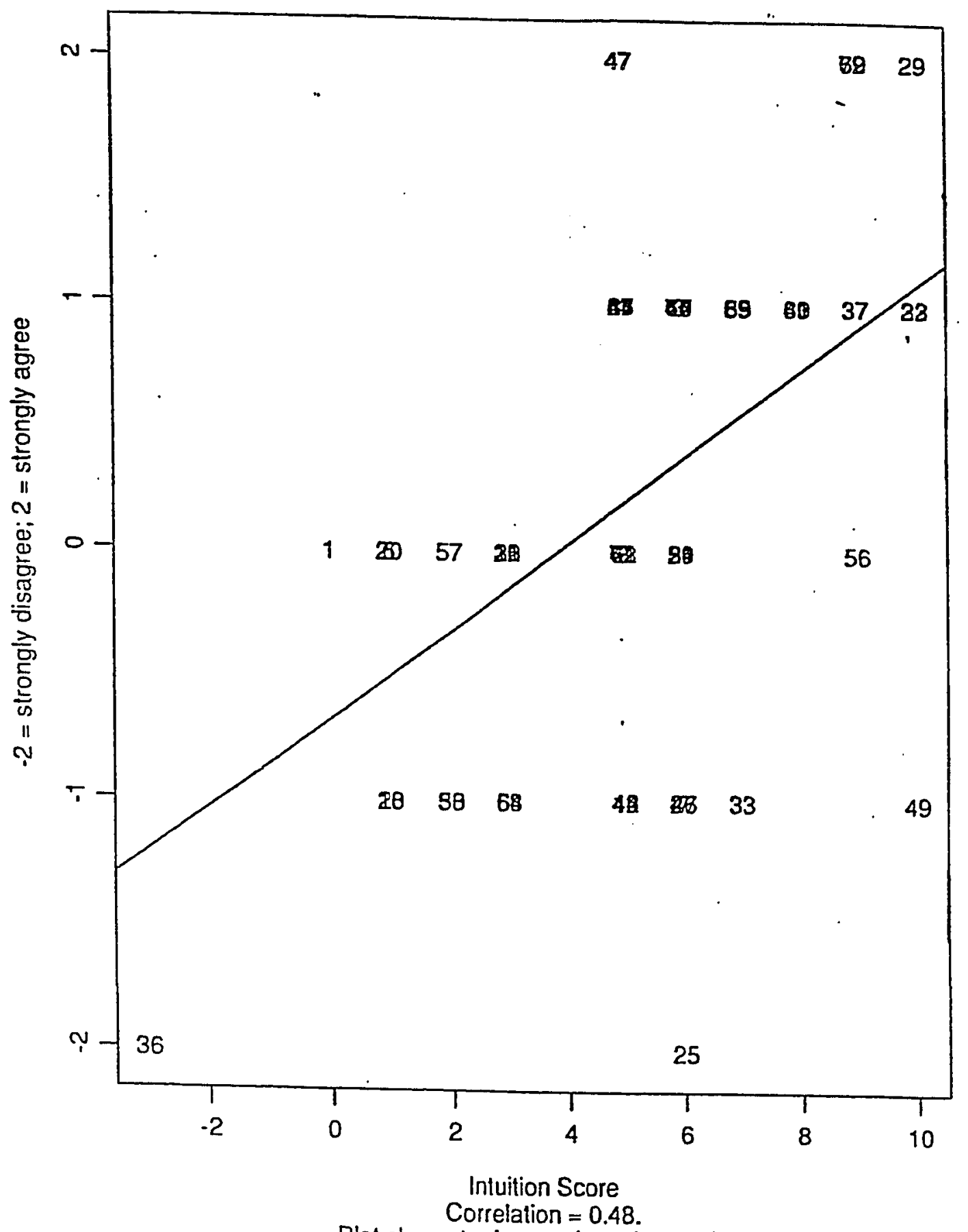

Plot characler is questionnaire number. 
question. The researcher examined the relationship between the respondents and non-respondents and the demographic information. There were no apparent associations between the subjects' race, age, sex, education, and whether the student responded to Question 7. However, there was a strong association between the subjects' primary language and whether they responded to question number 7 . Of the 30 subjects who did respond to question number 7, 29 stated their primary language was English.

The subjects who did provide examples described clinical situations in which they just "had a feeling" about a patient, but in which there was a lack of objective information to support their feelings. students stated that they used intuition in clinical situations to assess patients' physical and emotional well-being.

The actual responses to Item 7 were analyzed for common themes. The findings revealed that the students had difficulty describing and discussing the concept of intuition. This was demonstrated in various ways. Several of the subjects requested a definition, in order to make sure their definition matched the researcher's. Several subjects stated that they used intuition "all the time" but did not describe a specific situation. 
Findings: Phase Two

The qualitative portion of this research project was conducted by performing in-depth interviews with all 10 of the students who chose to participate. The interviews were directed toward ascertaining what meaning intuition had for the students. The interviews were taped, then transcribed and analyzed for major themes and meanings. Several categories were identified from the data having to do with how, where, and when intuition was experienced by the students.

First the researcher will describe how the students reported experiencing intuition in a spatial way, as if it had a "location." This will be followed by a discussion of how and when they reported experiencing intuition, the emotional response they described when they experienced intuition, and what value they placed on this phenomenon. Then there will be a discussion of the subjects' perceptions of the role education has in the development of their intuition.

Locating Intuition. During the process of the interviews, students repeatedly indicated that they experienced intuition in a spatial sense; that is, intuition was kinesthetically or spatially located. The subjects described the manifestation of intuition as occurring 
outside or inside of their body, or as a connection between themselves and another being. For other students the spatial location differed from one event to another.

The students who spoke of an inner location described intuition as part of their "subconscious," "a gut feeling," "a voice," "a funny feeling," "their inner self," or "inner voice." One student stated, "You feel it deep in your heart." Several of the students pointed to a specific part of their body as being the source of intuition. For instance one student pointed to her heart, another pressed her hands on her chest. These individuals described their intuition as an embodied experience.

The students who located intuition outside of themselves described intuition as "an angel on my shoulder," or "something that all of a sudden happens to me," or "you know, it's a voice that's from somewhere else." These individuals seemed to view intuition as not part of themselves. Intuition seems to be experienced by these individuals in a auditory form.

other students referred to intuition as being a connection between themselves and others. Several students explained it as a way of interpersonally relating to people including staff, patients, other students, and their clinical instructors. They described it as "means by which" 
they are able to "sense" what is going on with another individual. Several students stated that it was the way they communicated or connected with God. One student explained it as the way she was able to "connect with the collective unconscious." Others described it as a way of connecting with other people's auras.

The experience of intuition. The transcripts revealed similar patterns among the subjects' descriptions of their experience of intuition. First they described intuition as an experience of having obtained complete whole knowledge without learning it or without knowing or understanding the source of that knowledge. For example one student stated, "It is hard to say where it comes from, but all of a sudden you're standing there and you know; you don't know how you know but you know."

Secondly, they explained intuition as having a spontaneous, elusive quality. One student stated, "It just comes to me suddenly without warning." Another student described it as "a state of clarity."

Thirdly, students described their experience of intuition as having a robotic or automatic characteristic which was almost like a reflex. A student stated "After you do something over and over again it is automatic; you do it without having to think about what you are doing." 
Lastly, students characterized intuition as an experience similar to a premonition or a hunch which guides them to investigate alternative ways of thinking. Several students spoke of the experience as a directional clue. one student stated, "It causes me to just slow down and take a closer look." Another student verbalized, "It is like the gestalt: The picture just isn't right so it causes me to reflect and take a closer look, to reevaluate."

Timing of intuitive experiences. During the interviews the students discussed the timing of intuitive experiences. They report the occurrence of intuition more frequently when they felt an impending change in patient status, when an incongruence was sensed between verbal and non-verbal input, and/or when prioritizing nursing diagnoses and interventions.

Most commonly the students associated the experience of intuition within situations which involved a change in patient's status or within life and death situations. one student stated she "knew things were going down hill fast; you know, the patient had a funny smirk on his face." Another student stated, "When working in oncology you begin to sense if patients will do well or not, even if their prognosis is poor." 
Numerous students verbalized having a "gut feeling" that there was an incongruence between what was actually happening with a patient and what the patient verbalized. One student cited the example of assessing a patient for pain. The patient professed that she was not in pain and did not need any pain medication. However, based on an intuitive hunch the student nurse pressed the issue. In doing so, she discovered that the patient was fearful that she would lose consciousness if given pain medication. Many of the students stated that they would use their intuition while prioritizing patient problems. A student stated that intuitively he "just knew" that a patient's mother had "increased anxiety related to a knowledge deficit related to her child's spica cast." The student stated, "Immediately, I reassured her that I would teach her all she needed to know about the spica cast before she had to take her son home, and sure enough, she was able to relax."

Intuition as an emotionally charged topic. Throughout the interviewing process the students experienced an array of emotional responses. These responses ranged from fear and frustration, to pleasure, along with the feeling of being misunderstood.

Many of the subjects verbalized a sense of fear when discussing intuition. Some voiced fears about communicating 
their intuitive feelings and thoughts because of what they anticipated would be a negative reaction from their colleagues and hence being judged. Others said that the discussion of intuition involved risk taking which elicited fear.

One student expressed concerns about whether or not nursing practice was conducive to being intuitive. She stated, "I really worried quite a bit about whether or not nursing will allow you to be intuitive because of how rushed everything is."

Frustration occurred for one student when she did not verbalize her intuitive hunch. She stated, "I owe it to the patient to tell other staff members, but I didn't think they would believe me." One student verbalized frustration when she was unable to discern what it was that was making her feel uncomfortable about her patient's status.

Another student stated that she felt very misunderstood and said she did not think her colleagues understood her. This led to feelings of depression and a sense of isolation. Several of the students stated they were pleased when they had acted upon an intuitive hunch and it was accurate. One stated she felt "connectedness and wholeness" when she was in touch with the intuitive part of herself. 
A universal theme among the students was a desire to have their intuitive hunches validated and supported by either objective information or by staff members and or instructors. Most students conveyed the impression that intuition was a personal, private part of themselves.

Valuing intuition. The interviewees were asked questions concerning what value intuition had for them. The overall response was that they placed a tremendous value on their intuitive abilities. Only one student stated, "It is always right, although I try to ignore it." This student believed her "inner voice" was consistently valid; however, she attempted to disregard this form of knowledge. She credited her attempts to ignore her intuitive hunches to her strong willfulness.

The remaining 9 students spoke with high regard for their intuitive knowledge; they primarily trusted this feeling. Some students reported that their intuition was the absolute truth; others reported that they trusted it $95 \%$ of the time.

When the subjects discussed the value of intuition for nursing several students felt that an intuitive grasp is what separates an "excellent nurse from an average nurse." Another student stated, "It is what makes a nurse special." Most students felt that it was an essential part of nursing 
and without it you could not provide quality patient care. One student stated, "It is the ability to look at the whole person." Many of the students stated that common sense or intuition was what separated textbook knowledge from practical knowledge.

Intuition and nursing education. During the interviews the students were asked what role they felt their educational program should take in the development of their intuition. Without exception, all of the students felt it was imperative that the educational system address the use of intuition in nursing. Most students felt that intuition was an innate characteristic that could not be taught, but could be fostered. They viewed the role of education as a supportive one which should nurture their intuitive thinking ability.

A recurrent theme raised by most of the interviewees was the identification of the importance of the clinical instructors' attitudes towards the use of intuition in nursing practice. The students gave examples of those clinical instructors who fostered their use of intuition and those who did not. Many students voiced the opinion that the educational system gave conflicting messages regarding the use of intuition. One student cited an example of when an instructor questioned her choice of prioritization of 
client problems. She told the instructor that it was just "a gut feeling." The instructor replied, "What about the scientific backing?"

The students suggested strategies that would foster their development of intuition. These included postconference discussions, an increase in the number of hours spent in clinical practice, an open acceptance of the use of intuition in nursing practice, and clinical instructors' role modeling of intuition.

The context of intuition. The students discussed factors which influenced their ability to be intuitive. These factors included experience, environmental factors, knowledge of a particular client, and educational background.

Experience was a recurrent topic that was discussed. The students stated that not only did work experience. increase a person's intuitive abilities but also "life" experiences did. Students believed that repeated exposure to different situations increased their confidence and this, in turn, increased their ability to think and act intuitively.

The researcher asked the students to identify environmental influences which affected the students' ability to function intuitively. These included different 
clinical environments, stress, fatigue, and preoccupation with tasks. Many of the students stated the work environment was a key factor in whether or not the students' intuitive abilities were utilized. Individual students gave examples of different clinical settings which nurtured their use of intuition. Students cited environments in which they had had previous experience with the patient population and or a developed relationship with the staff. Stress was cited as a factor which both increased and decreased the students' intuitive ability. One student who works in the emergency room stated that stress increased her ability to function quickly and intuitively. Another student stated that a hospice setting was a low stress environment for her which provided her with a sense of "peacefulness that allows me to be more in touch with that part of myself."

Numerous students discussed the difficulty of thinking at an intuitive level when much emphasis is placed upon the completion of tasks. Many felt that they were concentrating heavily on the successful completion of a new tasks and that they were unable see anything else. One student stated that when she was tired she was much less able to perform on an intuitive level. 
Several students stated that the more they knew the individual patient the more able they were to sense the patient's physical and mental well being. They also stated that the more comfortable they felt in the environment and specialty area, the more intuitive they felt. This chapter summarized the findings of this study. The following chapter will discusses the author's conclusions and recommendations for further study. 
Chapter 5

CONCLUSIONS AND RECOMMENDATIONS

Historically, human beings have had a long term fascination with the phenomenon of intuition. This curiosity has been well documented since Aristotle's (382322 BC) contemplation of intuition (Bastick, 1982). Since then multiple disciplines have studied intuition and until this day there is little agreement among scholars as to the definition of intuition, the value of intuition, and the role intuition plays in learning or in the development of the personality. The only common thread among these great scholars may be the enthusiasm and exuberance with which they pursue the study of this fascinating phenomena. Nursing scholars are no exception; just recently we have begun to investigate the importance of intuition for nursing. Benner's (1984) research has indicated that an intuitive grasp of a clinical situation is a characteristic of the expert nurse. Rew (1988) has investigated how nurses experience intuition and how they use this valuable resource. Yet, nursing scholars are far from agreement as to the role intuition has in nursing practice. Mccain (1965) wrote that nursing was done "primarily intuitively" and she called for "a precise method of determining when 
nursing intervention is needed like medicine, law and engineering." A review of the nursing literature reveals that the professional body of nursing has neither embraced nor rejected the notion of a marriage between scientific and intuitive knowledge.

Disagreement among great nursing scholars as to the significance of intuition supports the need for more research to examine the specific role intuition has in nursing practice and nursing education. The intent of this research was to make a contribution to understanding just what that role is by addressing intuition and nursing students. This study is significant primarily because it is the first to investigate nursing students. Secondly, the findings strongly suggest that novice nursing students do experience intuitive hunches in their nursing practice, although they are uncertain of the appropriate use of this valuable tool.

The implications of this study involve both nursing practice and nursing education. Although the results of this study can not be generalized without further research, these findings suggest that nursing education may not have adequately addressed the development of intuitive thinking in novice nursing students. Nursing education has a responsibility to provide nursing students with skills that 
allow them to develop into expert nurses. Nursing educators need to focus attention on investigating how they address intuition in their curricula and how they themselves perceive and experience intuition.

The lack of established reliability and validity of the questionnaire is one limitation of this study. Reliable instruments in this field of study are lacking and the development of tools is essential for future research. Another limitation is the small sample size which precludes generalization of these findings to a larger population. Replication of this study with a similar population is suggested. Also, research extending this work by following these same students in 2 years would provide insight into the development of intuition in nursing students.

Rew's study (1988) indicates that when practicing nurses experience intuitive hunches they validate those feelings by looking for objective criteria which supports their intuitive hunch, or by consulting with colleagues. This researcher recommends further study to explore how student nurses use this information, whether they act on their intuitive hunches, and if so, what actions are taken. Other possible areas of research include investigation of the accuracy and validity of clinical intuition in both 
experienced practicing nurses and nursing students. Another essential area of study is the development of clinical intuition.

This research attempted to add to the existing literature by investigating nursing students and their experiences and perceptions of intuition in nursing practice. Research investigating the role of intuition in clinical decision making and nursing practice is in the infancy stage; therefore, more work needs to be accomplished before any conclusions can be made regarding the significance of intuition in nursing practice. 
REFERENCES 
References

Agan, D. R. (1987). Intuitive knowing as a dimension of nursing. Advances in Nursing Science, 10(1), 63-70.

Bastick, T. (1982). Intuition: How we think and act. Chichester: John Wiley \& Sons.

Benner, P. (1984). From novice to expert. Menlo Park, CA: Addison-Wesley.

Benner, P., \& Tanner, C. (1987). How expert nurses use intuition. American Journal of Nursing, 87(1), 23-31.

Benner, P., \& Wrubel, J. (1982). Skilled clinical

knowledge: The value of perceptual awareness. Nurse Educator, 7, 11-17.

Bloomquist, K. B. (1985). Evaluation of students: Intuition is important. Nurse Educator, $10(6), 8-11$.

Bruner, J. S. (1973). Beyond the information given. New York: W.W. Norton \& Co.

Carper, B. A. (1978). Fundamental patterns of knowing in nursing. Advances in Nursing Science, 1(1), 13-23.

Dreyfus, H. L. (1979). What computers can't do: The limits of artificial intelligence. New York: Harper \& Row. 
Dreyfus, H. L., \& Dreyfus, S. E. (1985). Mind over machine: The power of human intuition and expertise in the era of the computer. New York: New York Free Press.

Fallik, B., \& Eliot, E. (1986) Relation between intuition and college majors. Perceptual and Motor Skills, 63, 328.

Fallik, B., \& Eliot, E. (1985) Intuition, cognitive style, and hemispheric processing. Perceptual and Motor Skills, 60, 683-697.

Gerrity, P. L. (1987) . Perception in nursing: The value of intuition. Advances in Nursing Science, 1 (3), 63-71. Hammond, K. R. (1966) Clinical inference in nursing: A psychologist's viewpoint. Nursing Research, 15(1), $27-38$.

Hammond, K. R., Kelly, K. J., Schneider, R. J., \& Vancini, M. (1966). Clinical inference in nursing analyzing cognitive tasks representative of nursing problems. Nursing Research, 15(2), 134-138.

Kelly, K. (1966) Clinical inference in nursing: A nurse's viewpoint. Nursing Research, 15(1), 23-26.

Miller, V. G. \& Rew, L. (1989). Analysis and intuition: The need for both in nursing education. Journal of Nursing Education, $\underline{28}(2), 84-86$. 
McCain, F. R. (1965). Nursing by assessment-not intuition. American Journal of Nursing, 65(4), 82-84. 
Pyles, S. H., \& Stern, P. N. (1983). Discovery of nursing gestalt in critical care nursing: The importance of the gray gorilla syndrome. Image: The Journal of Nursing Scholarship, 15, (2), 51-57.

Rew, L. (1986). Intuition: Concept analysis of a group phenomenon. Advances in Nursing Science, $\underline{8}(2), 21-28$.

Rew, L. (1988). Intuition in decision making. Image: The Journal of Nursing Scholarship, 20, (3), 150-154.

Rew, L. (1987). IJursing intuition too powerful and too valuable to ignore. Nursing $87,17(7), 43-45$.

Rew, L., \& Barrow, E. M. (1987). Intuition: A neglected hallmark of nursing knowledge. Advances in Nursing Science, $10(1), 49-62$.

Schraeder, B. D., \& Fischer, D. K. (1987). Using intuitive knowledge in the neonatal intensive care nursery. Holistic Nursing Practice, $1(3), 45-51$.

Schraeder, B. D., \& Fischer, D. K. (1986). Using intuitive knowledge to make clinical decisions. Maternal Child Nursing, 11, 161-162.

Young, C. E. (1987). Intuition and nursing process. Holistic Nursing Practice, $1(3), 52-62$.

Wescott, M. R. (1968). Toward a contemporary psychology of intuition. New York: Holt, Rinehart \& Winston. 
Bibliography 


\section{Bibliography}

Chenitz, C., \& Swanson, J. (1986). From practice to

grounded theory. Menlo Park, CA: Addison-Wesley

Publishing Company.

Ferguson, M. (1980). The aquarian conspiracy. Los Angeles:

J.P. Tarcher, Inc.

Loyle, D. (1983). The sphinx and the rainbow; brain, mind, and future vision. Boulder, co: Shambhala.

Noddings, N., \& Shore, P. (1984). Awakening the inner eye;

intuition in education. New York: Teachers College

Press.

Paterson, J., \& Zderad, L. (1988) - Humanistic Nursing. New

York: National League for Nursing.

Progogg, I. (1973). Jung, synchronicity, and human destiny:

C.G. Jung's theory of meaningful coincidence. New

York:Julian Press. 
APPENDIX A

Cover Letter 
Appendix A

San Jose State University

Department of Nursing

Dear Semester 5 Nursing student:

I am Heather Collie, a graduate student at San Jose state University. I need your help in conducting a study that is exploring the use of intuitive knowledge in nursing. The results of this study should increase our understanding of how nursing students view intuition.

Attached is a short questionnaire and a demographic sheet. Filling out and returning them indicates that you have given informed consent to participate in this study, but do not include your name on these forms.

Your participation in this study is totally voluntary. If you do not want to participate, do not fill in the information and return them to the investigator.

The second phase of this research is an individual interview with me, the researcher. Completion of the questionnaire and demographic sheet does not obligate you to participate further in this research study. If you are interested in participating in an interview about intuition, please provide your name and phone number on the separate sheet provided.

If you have any questions about this study, I would be happy to talk with you. I can be reached at 924-3130.

Cordially,

Heather A.M. Collie, R.N. 
APPENDIX B

Demographic sheet 


\author{
Appendix B \\ San Jose State University \\ Department of Nursing \\ Demographic sheet
}

Please fill in the following blanks or circle the appropriate answers. Remember all information is confidential.

Age:

Have you ever worked with patients in an acute care setting? Yes or No

If yes please describe the work and length of employment.

Have you ever worked with patients in a subacute care setting?

Yes or No

If yes please describe the work and length of employment.

Highest level of education completed:

High School

- Associate Degree

- Bachelors Degree (if so what field)

- Graduate Degree (if so what field)

Total number of years employed in health care? none

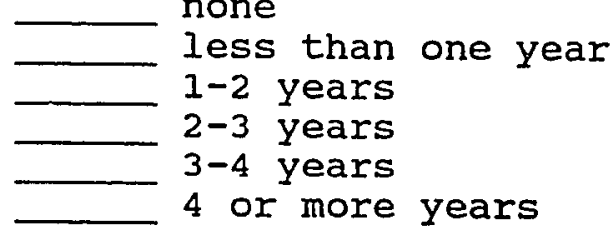

Primary Language:

Race: Asian Caucasian Hispanic Black other

Sex:

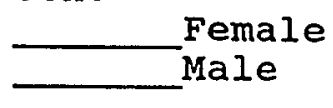


APPENDIX C

Questionnaire 


\section{Appendix C \\ San Jose State University \\ Department of Nursing \\ Questionnaire}

1) I think providing good nursing care involves the use of intuition.

Strongly Agree Agree Indifferent Disagree Strongly

Disagree

2) I believe providing good nursing care involves the use of both scientific and intuitive modes of thinking.

Strongly Agree Agree Indifferent Disagree Strongly

Disagree

3) The longer I am a nurse the less I will use intuition in clinical practice.

Strongly Agree Agree Indifferent Disagree Strongly

Disagree

4) My nursing program supports my use of intuition.

Strongly Agree Agree Indifferent Disagree Strongly

Disagree

5) I personally have used intuition while working in nursing.

Strongly Agree Agree Indifferent Disagree Strongly

Disagree

6) I frequently use intuition when caring for patients

Strongly Agree Agree Indifferent Disagree strongly

Disagree

7) Describe a clinical situation when you used, or observed intuition being used. 
APPENDIX D

Contact Letter 
Appendix D

\section{San Jose State University}

Department of Nursing

I would be glad to have you contact me for an interview for your research project on intuition.

Name:

Phone: 
APPENDIX E

Consent Form 


\author{
Appendix E \\ San Jose State University \\ Department of Nursing \\ Consent to Participate in A Research Study
}

You have been invited to participate in a research study. The purpose of this study is to explore the use of intuitive knowledge in clinical nursing. If you decide to participate in this study, you will be interviewed about your ideas concerning intuition and nursing practice. The interview will last appropriately one hour.

There is a potential risk of loss of confidentiality. Confidentiality will be protected as well as possible under the law. All information obtained during this study will be coded with numbers and no names will be stored with the data. Your decision to participate or not will not prejudice your future relations with the researcher, the nursing department, or San Jose State University. If you decide to participate, you are free to withdraw at any time. Although this research is not expected to benefit you, you may find some personal value by being able to discuss your views on intuition in nursing.

If you have further questions about the study, you may contact the researcher, Heather collie, at (408) 924-3164. If you wish to discuss this research with someone other than the researcher you may contact Dr. Gorenberg, Graduate Coordinator, at (408) 924-3130, or Serena stanford, Associate Academic Vice President for Graduate studies, at (408) 924-2480.

I HAVE MADE A DECISION WHETHER OR NOT TO PARTICIPATE. MY SIGNATURE INDICATES THAT I HAVE READ THE INFORMATION PROVIDED ABOVE AND THAT I HAVE DECIDED TO PARTICIPATE.

SUBJECT'S

SIGNAMTRE

INVESTIGATOR'S

SIGNATURE

DATE 
APPENDIX F

Interview Guide

65 


\section{Appendix F \\ Interview Guide}

1) How would you define intuition?

2) Have you ever had an intuitive experience in your nursing practice.

3) Describe a time when you think you used intuition?

4) How do you see this nursing program influencing your intuition?

5) How do you think your Nursing education could foster your use of intuition? 
Appendix G

IRB Approval Letter 
Appendix G

IRB Approval. Letter

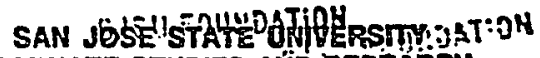 GRADUATE STUDIES AND AESEÄBCH

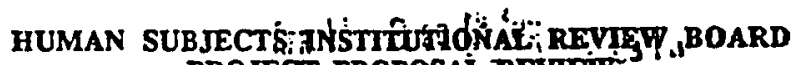 PROJECT PROPOSAI, REVIEW}

Regular Review

Expoditod Roviow

Deadine Dab

1, the undersigned member of the San Jose State University Human Subjects Institutional Review Board, have reviewed the following proposal submitted to the Board on $4 / 4 / 89$ by:

\begin{tabular}{l} 
PRINCIPAL INVESTIGATOR: Heather A.H. COllie \\
PROTOCOL \#: 7483 \\
PROJECT TITLE: STUDENT NURSES EXPERIENCE \& PERCEPTIÖNS OE INTIIUIVE \\
\hline KNOWLEDGE IN NURSING PRACTICE
\end{tabular}

i recommend the foliowing action (incicate one):

1. Approved for clearance as involving minimal risk to Human Subjects.

$\not$

2. Approved for clearance with risk to Human Subjects.

3. Approval depends upon the satisfactory completion of the following conditions.

4. I have serious concerns about this protocol and it should go belore the full committee to review.

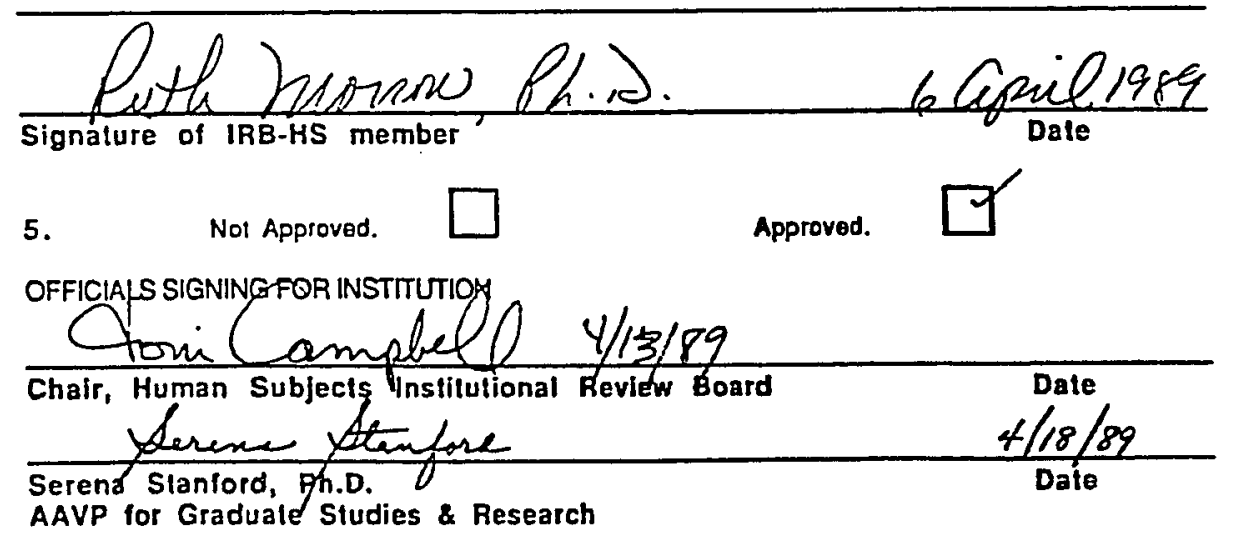

Please relurn 10: San Jose State University Foundation, One Washington Square, San Jose, CA 95isz-0139 (408) $924-1438$ 